
$\angle$ Research Square
Preprints are preliminary reports that have not undergone peer review.
They should not be considered conclusive, used to inform clinical practice, or referenced by the media as validated information.

\title{
Elucidation of Melanin Pigment Production From A Promising Locally Isolated Halotolerant Black Yeast Hortaea Werneckii AS1
}

\author{
Asmaa Elsayis \\ National Institute of Oceanography and Fisheries (NIOF) \\ Sahar W. M. Hassan \\ National Institute of Oceanography and Fisheries (NIOF) \\ Khaled M. Ghanem \\ Alexandria University \\ Heba Khairy ( $\sim$ heba.khairy@alexu.edu.eg ) \\ Alexandria University
}

Research Article

Keywords: Melanin, black yeast, Hortaea werneckii, Plackett-Burman design, Box-Behnken.

Posted Date: February 3rd, 2022

DOI: https://doi.org/10.21203/rs.3.rs-1273016/v1

License: (c) (1) This work is licensed under a Creative Commons Attribution 4.0 International License. Read Full License 


\section{Abstract}

Background: Melanins are one of the magnificent natural pigments synthesized by a wide range of microorganisms including different species of fungi and bacteria. Marine black yeasts appear to be potential prospects for the synthesis of natural melanin pigment production. As a result, the goal of this research was to isolate a promising marine black yeast melanin-producing strain and improve the culturing conditions in order to maximize the yield of such a valuable pigment.

Results: Among six locally isolated black yeast strains, the only one that demonstrated a potent remarkable melanin pigment production was Identified using 18s rRNA as Hortaea werneckii AS1. The extracted pigment's physiochemical characterization and analytical investigation with Ultraviolet-Visible (UV) spectrophotometry, Fourier Transform-Infrared spectroscopy (FTIR), and Scanning Electron Microscope (SEM) confirmed its nature as a melanin pigment. The data obtained from the polynomial model's maximum point suggested that $\mathrm{CaCl}_{2}, 1.125(\mathrm{~g} / \mathrm{L})$; trace element, 0.25 $(\mathrm{ml} / \mathrm{L})$; and a culture volume $225(\mathrm{ml} / 500 \mathrm{ml})$ at their optimal values were the critical three elements impacting melanin production. In comparison with the baseline settings, the response surface methodology (RSM) optimization approach resulted in a 2.0 - fold improvement in melanin output.

Conclusions: A Maximum melanin yield of $0.938 \mathrm{~g} / \mathrm{L}$ proved the halotolerant $H$. werneckii AS1 potentiality as a source for natural melanin pigment synthesis 'when compared to some relevant black yeast strains' and hence, facilitating its incorporation in a variety of pharmaceutical and environmental applications.

\section{Background}

Melanin pigments are a class of high molecular weight metabolites displayed in dark colors ranging from brown to black, which is harmonized from phenolic or indolic compounds and often present in complexes with proteins or carbohydrates [1,2]. Principally, their formation backs to either the auto-oxidation process of the phenolic compounds in the medium or enzymatically through the action of tyrosinase and polyketide synthase as key enzymes in melanogenesis [3]. Marine fungi involve a particular group of black yeasts capable of producing these valuable coloring metabolites as it has a fundamental role in standing the extreme environmental conditions $[4,5,6]$.

Black yeasts as polymorphic fungi, they showed yeast-like, filamentous, and meristematic growth. Their hyphal growth is demonstrated on solidified media, predominantly [7, 8]. Because of melanin, melanized yeast-like fungi are dominant in high saline environments [9]. Melanin provides the fungal cells with high level of protection in the face of various environmental stresses, mainly UV radiation [10], oxidative stress [11], the toxic effect of heavy metals and radiation, and high salt concentrations $[12,13,14]$. The melanin producing ascomycetous fungi associated with order Dothideales or Capnodiales is considered the predominant black yeasts in salterns, for example; Hortaea werneckii, Aureobasidium pullulans, Trimmatostroma salinum, Phaeotheca triangularis, in addition to phylogenetically relevant Cladosporium species $[15,16,17]$.

H. werneckii species among saltern's black yeasts, has received the most attention. It is an extremely halotolerant species [17] that withstand salinities ( $\mathrm{NaCl}$ concentrations) in the range of $0 \%$ to saturation $32 \%(\mathrm{w} / \mathrm{v})$, with optimal growth at 6-10\% $(\mathrm{w} / \mathrm{v})[18,19,20]$. As a result, it was spotted in a variety of salty habitats, including seawater, sea sponges, mangrove plants, as well as salted foods [21, 9, 22]. Despite the fact that $H$. werneckii has been documented to synthesize dihydroxynaphthalene (DHN) type of melanin under both saline and non-saline conditions of growth [23], melanin granules were salt-based distributed in the outer part of the melanized cell wall, allowing $H$. werneckii to successfully minimize the permeability for the main compatible solute glycerol through reducing pores size in the cell wall. This mechanism could be one of the characteristics that contribute to its tolerance to a wide range of salt concentrations $[24,25]$.

Distinctive properties of melanins allow their participation in a wide range of applications among various fields. First, medical applications include antimicrobial, antiviral, antitumor, antioxidant, and anti-inflammation [26, 27, 28, 29]. Second, pharmaceutical and cosmetic applications because of their capacity to absorb broad spectrum electromagnetic radiation ranging from visible light and ultraviolet radiation to the X-rays [30, 31, 32]. Third, environmental application in bioremediation of contaminated sites backing to their capacity of binding heavy metals and radionuclides [33].

Depending on their useful proprieties and ability to be used in a variety of applications, there is a growing demand for melanin production [34]. Furthermore, marine species as a source for the production of microbial melanin pigment, in particular, is an appealing option for both researchers and industries due to a variety of criteria such as being safe, easily degradable, and eco-friendly without causing adverse side effects [35]. From this point of view, our work aimed first for isolation of promising melanin-producing strain from Egyptian marine habitat, followed by, characterization and enhancement of melanin pigment production using a mathematical technique for conditions optimization in order to reach the maximum melanin yield.

\section{Results}

\section{Screening for a promising melanin pigment producing isolate}

Five melanized isolates (AS1 to AS5) were recovered from local salt marshes marine habitat using various sediment and water samples. Two isolates (AS3 and AS4) were obtained from water samples, while (AS1, AS2, and AS5) were recovered from sediments. All of the obtained isolates appeared to have dark brown to black colored colonies on SDA plates supplemented with L-tyrosine and $10 \%$ sodium chloride and were considered as potential 
melanin pigment producers. Melanin production of the five isolates was investigated under both shaking (180 rpm) and static conditions, results revealed that shaking is a must for growth and melanin production by all of them. Furthermore, AS1 isolate) Additional File 1, Fig. 1) among all of them showed the highest yield in both biomass and melanin recording $9.3 \mathrm{~g} / \mathrm{L}$ and $0.420 \mathrm{~g} / \mathrm{L}$, respectively (Additional File 1, Fig. 2). Therefore, AS1 was used for further experiments.

\section{Molecular Identification \& Phylogenetic Relationship Of The Potent Isolate}

The promising black yeast isolate AS1 was identified using Internal Transcribed Spacer (ITS) sequencing. This strategy resulted in 536 base pairs of sequencing data. This sequence was compared to those with the highest homology using the Blast search computer-based program. The results showed that the isolate AS1 under investigation had a high degree of similarity to the genera Hortaea sp. BLAST analysis confirmed 99 percent similarity of strain AS1 to the genus Hortaea werneckii. GenBank sequence database was where the nucleotide sequence has been deposited under the accession number (MW187022). In addition, the isolate was deposited in Assuit University Mycological Center with the number (AUMC 14501).

The phylogenetic position of $H$. werneckii AS1 and the closely related relatives were analyzed using neighbor-joining dendrogram as shown in (Fig. 1). The neighbor-joining tree indicated that the strain AS 1 is closely related to the $H$. werneckii. Furthermore, the strain AS 1 differs phylogenetically by making a separate lineage, which may support it to be a new strain.

\section{Melanin Characterization}

\section{Solubility characterization}

Melanin's unique solubility and reactivity properties allowed the usage of conventional physicochemical tests as a primary step towards the identification and characterization of the produced pigment. H. werneckii AS1 extracted dark pigment was chemically characterized and results revealed that it was insoluble in either water or most of the organic solvents tested (butanol, chloroform, ethyl acetate, and hexane). On the other hand, the pigment showed a slight solubility in both ethanol and methanol solvents. Also, the pigment was observed to be radially soluble only in a sodium hydroxide $(1 \mathrm{~N})$ solution, and after vigorous shaking in dimethyl sulfoxide (DMSO). Moreover, it exhibited precipitation in $1 \%$ ferric chloride solution and decolorized by hydrogen peroxide 30\% (v/v) (Additional File 1. Fig. 3). The solubility tests of the melanin standard were performed in parallel with the extracted pigment and recorded the same results.

\section{Spectrophotometric analysis}

The extracted pigment in parallel with melanin standard (Sigma Aldrich) were spectrophotometrically analyzed in a wavelength range of (200-800 $\mathrm{nm}$ ) (Fig. 2a, 2b). A similar pattern of UV-visible absorption spectrum of the biosynthesized melanin and synthetic melanin were obtained, revealing that absorption peak was at UV region and declined towards the visible region with maximum points of absorption at $240 \mathrm{~nm}$ and $219 \mathrm{~nm}$, respectively.

\section{Fourier transform-infrared (FT-IR) analysis}

The obtained FTIR spectrum of the pigment derived from H. wernekii AS1 (Fig. 3a) showed a number of significant peaks near $3438.31 \mathrm{~cm}^{-1}, 2927.31$ $\mathrm{cm}^{-1}, 1637.53 \mathrm{~cm}^{-1}$, and $1239.90 \mathrm{~cm}^{-1}$. The result was compared to a melanin standard acquired from Sigma Aldrich (Fig. $3 \mathrm{~b}$ ). The most noticeable difference between $H$. werneckii AS1 pigment and synthetic melanin standard is the peak at $2927 \mathrm{~cm}^{-1}$, which also implies the presence of a considerable amount of aliphatic groups in the investigated melanin structure.

\section{Elemental analysis}

The amounts of nitrogen, carbon, hydrogen, and sulphur in both the extracted pigment and melanin standard were detected through the elemental analysis. The elemental structure of extracted pigment showed higher percentages of hydrogen and sulphur (5.644\% and $0.877 \%$ in comparison with synthetic melanin (3.196\% and $0.582 \%)$, respectively. On the other hand, the extracted pigment's carbon and nitrogen contents (43.35\% and 5.48) were almost similar to synthetic melanin values (47.82\% and $5.78 \%)$, respectively.

\section{Scanning electron microscope of the derived melanin pigment}

The morphological characterization and structural arrangement of the extracted pigment in parallel with synthetic melanin have been analyzed by SEM and revealed that $H$. werneckii AS1 pigment has a definite crystal shape besides, structures appear like yeast cells (Fig. 4a, 4c). The extracted pigment particle's average size lies between $(130-160 \mathrm{~nm})$ (Fig. 4b), with a slight difference from the synthetic standard melanin range (125-240 nm) (Fig. 4d).

\section{Optimization Of Melanin Pigment Production} Effect of incubation period on growth and melanin production 
The incubation period's impact (1-11 days) over several criteria like dry weight and mainly melanin yield was studied. As illustrated in (Additional File

1, Fig. 4), the biomass dry weight and maximum melanin yield were achieved in the 9 th and 10 th days of incubation with about $11.4 \mathrm{~g} / \mathrm{L}$ and 0.44 $\mathrm{g} / \mathrm{L}$, respectively, then the numbers had started in decreasing gradually. Observation of time course of melanin production and time of incubation showed that the yield level increased after the 5th day and reached its maximum on the 10th day (stationary phase of growth). Similar results were noticed regarding the dry weight with a slight difference in having the maximum yield in the 9th day and started to decrease afterward.

\section{Different sodium chloride concentrations effect on the isolate's growth and melanin synthesis}

The impact of various concentrations of sodium chloride on $H$. werneckii AS1 dry weight and melanin productivity was tested) Additional File 1,

Fig. 5). Melanin production dropped as sodium chloride concentrations increased, with the highest output (0.469 $\mathrm{g} / \mathrm{l})$ recorded at $3.5 \%$ salinity (seawater salinity) and the lowest yield $(0.073 \mathrm{~g} / \mathrm{L})$ observed at $20 \%$ salinity in a medium prepared with sea water. The optimum growth rate and biomass productivity of $H$. werneckii AS1 were at about $13.5 \%$ salinity with a $13.8 \mathrm{~g} / \mathrm{l}$ yield.

\section{Optimization of different medium components by Plackett- Burman (PB) design of experiment}

In order to assess the relative relevance of several influences on biomass and melanin synthesis in submerged cultures, Plackett-Burman experimental design was employed. Elven variables were examined in PB experiments and the experimental results indicated as showed in Table (1) that the most productive trial was (trial 6) with the highest melanin productivity of about $(0.876 \mathrm{~g} / \mathrm{L})$. For each independent variable, the main effect as well as t-values, were calculated (Table 1)

Table 1

The applied Plackett-Burman experimental design and the statistical analysis for twelve cultural variables for the production of melanin pigment by H. werneckii AS1

\begin{tabular}{|c|c|c|c|c|c|c|c|c|c|c|c|c|}
\hline \multirow[t]{2}{*}{ Trial } & \multicolumn{10}{|c|}{ Factor symbol } & \multicolumn{2}{|c|}{ Response } \\
\hline & $\begin{array}{l}\text { Glucose } \\
((\mathrm{g} / \mathrm{l})\end{array}$ & $\begin{array}{l}\mathrm{KNO}_{3} \\
(\mathrm{~g} / \mathrm{l})\end{array}$ & $\begin{array}{l}\mathrm{K}_{2} \mathrm{HPO}_{4} \\
(\mathrm{~g} / \mathrm{l})\end{array}$ & $\begin{array}{l}\mathrm{CaCl}_{2} \\
(\mathrm{~g} / \mathrm{l})\end{array}$ & $\begin{array}{l}\mathrm{MgSO}_{4} \\
(\mathrm{~g} / \mathrm{l})\end{array}$ & $\begin{array}{l}\text { Tyrosine } \\
\text { (gVI) }\end{array}$ & $\begin{array}{l}\text { Trace } \\
\text { element } \\
\text { (ml/l) }\end{array}$ & $\mathrm{pH}$ & $\begin{array}{l}\text { Culture } \\
\text { age } \\
\text { (day) }\end{array}$ & $\begin{array}{l}\text { Inoculum } \\
\text { size } \\
\text { (ml/l) }\end{array}$ & $\begin{array}{l}\text { Volume } \\
(\mathrm{ml} / 500 \mathrm{ml})\end{array}$ & $\begin{array}{l}\text { Melanin } \\
(\mathrm{g} / \mathrm{l} / \mathrm{)})\end{array}$ \\
\hline 1 & $-1[10]$ & $-1[7.5]$ & $-1[1.25]$ & $+1[0.75]$ & $+1[1.5]$ & $+1[1.5]$ & $-1[0.5]$ & $+1[6.5]$ & $+1[10]$ & $-1[0.5]$ & $+1[150]$ & 0.538 \\
\hline 2 & $-1[10]$ & $-1[7.5]$ & $+1[3.75]$ & $+1[0.75]$ & $+1[1.5]$ & $-1[0.5]$ & $+1[1.5]$ & $+1[6.5]$ & $-1[4]$ & $+1[1.5]$ & $-1[50]$ & 0.217 \\
\hline 3 & $-1[10]$ & $+1[22.5]$ & $-1[1.25]$ & $-1[0.25]$ & $-1[0.5]$ & $+1[1.5]$ & $+1[1.5]$ & $+1[6.5]$ & $-1[4]$ & $+1[1.5]$ & $+1[150]$ & 0.327 \\
\hline 4 & $+1[30]$ & $+1[22.5]$ & $-1[1.25]$ & $+1[0.75]$ & $-1[0.5]$ & $-1[0.5]$ & $-1[0.5]$ & $+1[6.5]$ & $+1[10]$ & $+1[1.5]$ & $-1[50]$ & 0.531 \\
\hline 5 & $-1[10]$ & $+1[22.5]$ & $+1[3.75]$ & $-1[0.25]$ & $+1[1.5]$ & $-1[0.5]$ & $-1[0.5]$ & $-1[4.5]$ & $+1[10]$ & $+1[1.5]$ & $+1[150]$ & 0.340 \\
\hline 6 & $+1[30]$ & $-1[7.5]$ & $+1[3.75]$ & $+1[0.75]$ & $-1[0.5]$ & $+1[1.5]$ & $-1[0.5]$ & $-1[4.5]$ & $-1[4]$ & $+1[1.5]$ & $+1[150]$ & 0.876 \\
\hline 7 & $+1[30]$ & $-1[7.5]$ & $+1[3.75]$ & $-1[0.25]$ & $-1[0.5]$ & $-1[0.5]$ & $+1[1.5]$ & $+1[6.5]$ & $+1[10]$ & $-1[0.5]$ & $+1[150]$ & 0.219 \\
\hline 8 & $+1[30]$ & $-1[7.5]$ & $-1[1.25]$ & $-1[0.25]$ & $+1[1.5]$ & $+1[1.5]$ & $+1[1.5]$ & $-1[4.5]$ & $+1[10]$ & $+1[1.5]$ & $-1[50]$ & 0.029 \\
\hline 9 & $+1[30]$ & $+1[22.5]$ & $+1[3.75]$ & $-1[0.25]$ & $+1[1.5]$ & $+1[1.5]$ & $-1[0.5]$ & $+1[6.5]$ & $-1[4]$ & $-1[0.5]$ & $-1[50]$ & 0.046 \\
\hline 10 & $-1[10]$ & $-1[7.5]$ & $-1[1.25]$ & $-1[0.25]$ & $-1[0.5]$ & $-1[0.5]$ & $-1[0.5]$ & $-1[4.5]$ & $-1[4]$ & $-1[0.5]$ & $-1[50]$ & 0.091 \\
\hline 11 & $-1[10]$ & $+1[22.5]$ & $+1[3.75]$ & $+1[0.75]$ & $-1[0.5]$ & $+1[1.5]$ & $+1[1.5]$ & $-1[4.5]$ & $+1[10]$ & $-1[0.5]$ & $-1[50]$ & 0.153 \\
\hline 12 & $+1[30]$ & $+1[22.5]$ & $-1[1.25]$ & $+1[0.75]$ & $+1[1.5]$ & $-1[0.5]$ & $+1[1.5]$ & $-1[4.5]$ & $-1[4]$ & $-1[0.5]$ & $+1[150]$ & 0.598 \\
\hline 13 & $0[20]$ & $0[15]$ & $0[2.5]$ & $0[0.5]$ & $0[1]$ & $0[1]$ & $0[1]$ & $0[5.5]$ & $0[7]$ & $0[1]$ & $0[100]$ & 0.431 \\
\hline $\begin{array}{l}\text { Main } \\
\text { effect }\end{array}$ & 0.11 & 0.004 & -0.044 & 0.31 & -0.07 & -0.005 & -0.15 & -0.035 & -0.06 & 0.11 & 0.31 & \\
\hline $\begin{array}{l}\text { t- } \\
\text { value }\end{array}$ & 0.69 & 0.02 & 0.28 & 2.53 & 0.46 & 0.02 & 1.0 & 0.22 & 0.37 & 0.73 & 2.47 & \\
\hline
\end{tabular}

$t$-value significant at the $1 \%$ level $=3.70$

$t$-value significant at the $5 \%$ level $=2.446$

$t$-value significant at the $10 \%$ level $=1.94$

$t$-value significant at the $20 \%$ level $=1.372$ 
According to the obtained results, calcium chloride, culture volume and trace element were the most significant independent variable that affects melanin production by $\mathrm{H}$. werneckii AS1 with a $t$-values of $2.53,2.47$ and 1.0 , respectively. Also, the main effect results demonstrated that a positive level of calcium chloride and culture volume, in addition to the negative level of trace elements aided in the melanin formation.

An experiment of verification was used to compare the estimated ideal levels of independent variables and the baseline settings to assess the perfection of the practiced Plackett-Burman statistical design. Results indicated that melanin productivity increased to $0.509 \mathrm{~g} / \mathrm{L}$ with a $1.23-\mathrm{fold}$ increase in comparison with the product obtained under the basal conditions.

\section{Growth parameters optimization using Box Behnken (BB) design}

The most important independent factors suggested by the Plackett-Burman design were investigated using Box Behnken (BB) design. The design matrix and the concentration of pigment response $(\mathrm{g} / \mathrm{L}$ ) of each trial were illustrated in (Table 2). The determination coefficient R2 for pigment production was 0.853 for this experiment, showing a remarkable degree of relation among experimental and predicted values. A polynomial function of second-order was fitted to the response results of the experiment (nonlinear optimization algorithm) to anticipate the ideal variable values;

$\left(Y=0.64+0.13625 X_{1}+0.015 X_{2}+0.22875 X_{3}-0.045 X_{1} X_{2}-0.0825 X_{1} X_{3}+0.015 X_{2} X_{3}+0.09125 X_{1}^{2}+0.02375 X_{2}^{2}-0.05875 X_{3}^{2}\right)$

Table 2

Box-Behnken factorial experimental design for melanin pigment production by Hortaea werneckii AS1

\begin{tabular}{|lllll|}
\hline Runs & Experimental parameters & \multicolumn{2}{c|}{ Response (g/l) } \\
\cline { 2 - 4 } & CaCl2 (g/l) & Trace element(ml/l) & Culture volume (ml/500ml) & \\
\hline 2 & $0[0.75]$ & $0[0.5]$ & $0[150]$ & 0.58 \\
\hline 3 & $-1[0.375]$ & $1[0.75]$ & $0[150]$ & 0.59 \\
\hline 4 & $0[0.75]$ & $-1[0.25]$ & $-1[75]$ & 0.44 \\
\hline 5 & $0[0.75]$ & $1[0.75]$ & $-1[75]$ & 0.51 \\
\hline 6 & $1[1.125]$ & $-1[0.25]$ & $-1[75]$ & 0.41 \\
\hline 7 & $-1[0.375]$ & $-1[0.25]$ & $0[150]$ & 1.01 \\
\hline 8 & $0[0.75]$ & $1[0.75]$ & $0[150]$ & 0.44 \\
\hline 9 & $1[1.125]$ & $0[0.5]$ & $1[225]$ & 0.8 \\
\hline 10 & $0[0.75]$ & $0[0.5]$ & $1[225]$ & 0.9 \\
\hline 11 & $0[0.75]$ & $-1[0.25]$ & $0[150]$ & 0.69 \\
\hline 12 & $-1[0.375]$ & $0[0.5]$ & $1[225]$ & 0.77 \\
\hline 13 & $-1[0.375]$ & $0[0.5]$ & $-1[75]$ & 0.28 \\
\hline 14 & $1[1.125]$ & $1[0.75]$ & $1[225]$ & 1 \\
\hline 15 & $0[0.75]$ & $0[0.5]$ & $0[150]$ & 0.98 \\
\hline
\end{tabular}

The optimal degree of the 3 factors as determined from the polynomial model's maximum point, were calculated by applying the solver function of the (Microsoft Excel 2019) tools and detected to be (calcium chloride, $1.125 \mathrm{~g}$; Trace element, $0.25 \mathrm{ml}$, and Culture volume $225 \mathrm{ml}$ ) with a predicted melanin yield of $0.994 \mathrm{~g} / \mathrm{L}$.

A three-dimensional (3D) response surface curves by STATISTICA 14.0 software were plotted, in order to reveal the interaction effects and ideal grade of the variables (Fig. 5a, 5b and 5c). As illustrated in (Fig. 5a), an interaction between calcium chloride and culture volume at their high values was recognized where, the maximum level of melanin synthesis was documented. On the other hand, the curve had its maximum response near the trace element low values (Fig. 5b). Previously mentioned results indicated that high calcium chloride with minimum trace element values were supportive in increasing melanin productivity by $\mathrm{H}$. werneckii AS1. Besides, in (Fig. $5 \mathrm{c}$ ) curve had its maximum along the trace element axis near its lower levels indicating that high culture volume with low trace element concentrations gave the highest amount of melanin.

As a result, the polynomial model's maximum point determined the optimal values of the three factors and were recorded as calcium chloride, 1.125 ( $\mathrm{g} / \mathrm{L})$; trace element, $0.25(\mathrm{ml} / \mathrm{L})$, and a culture volume $225 \mathrm{ml}$. 
The experimentally validated optimal conditions from the optimization experiment were put in comparison with the data calculated from the model. The maximum amount of melanin produced $(0.938 \mathrm{~g} / \mathrm{L})$ was obtained, which was slightly lower than the model's predicted value $(0.994 \mathrm{~g} / \mathrm{L})$. The model's validity was demonstrated by the tight corelation between experimental and predicted values.

Asecond verification experiment was performed to compare the productivity of the basal and the optimized medium, and data represented that melanin productivity in the optimized one was about 1.45 fold higher than the basal medium $(0.646 \mathrm{~g} / \mathrm{L})$.

From previously illustrated data it can be predicted that in order to obtain the highest yield of melanin pigment by $\mathrm{H}$. werneckii AS1, the medium needs to be formulated as following $(\mathrm{g} / \mathrm{L})$ : glucose, $30 ; \mathrm{KNO}_{3}, 22.5 ; \mathrm{K}_{2} \mathrm{HPO}_{4}, 1.25 ; \mathrm{MgSO}_{4} .7 \mathrm{H}_{2} \mathrm{O}, 0.5 ; \mathrm{CaCl}_{2} .2 \mathrm{H}_{2} \mathrm{O}, 1.125$; tyrosine, 0.5 ; trace element, $0.25 \mathrm{ml}$; culture age, 4 days; inoculum size, $1.5 \mathrm{ml}$; culture volume, 225 adjusted to $\mathrm{pH} 4.5$ and incubation period 10 days at $30{ }^{\circ} \mathrm{C}$ with agitation speed $180 \mathrm{rpm}$.

Previously mentioned results, revealed that $H$. werneckii AS1 is a promising locally isolated black yeast strain proved to synthesize melanin pigment in a considerable amount.

\section{Discussion}

Hortaea werneckii strain isolated in our study from marsh, which is considered as a biological source of melanin pigment has been documented as an extremely halotolerant fungus [37], and was recurrently isolated from natural hypersaline habitats all over the world [38]. In accordance, A three black yeast strains (EGYNDA08, EGYNDA16, and EGYNDA90) that was identified as $H$. werneckii were isolated from the Egyptian offshore salt marshes [39]. In addition, under optimal conditions, $H$. werneckii EGYNDA08 was able to tolerate $\mathrm{NaCl}$ concentrations of up to $25 \%$ and significantly produce a dark brown melanin pigment of up to $228 \mathrm{mg} / \mathrm{L}$ [1]. Also, an extremophilic black yeast $H$. werneckii strain was reported to be isolated from decayed leaves from the Red Sea mangroves [3].

The direct effect of agitation on $\mathrm{H}$. werneckii productivity of melanin may back to the fact that most aerobic microorganism's processes are governed by the rate of oxygen transfer from air to liquid cultivation media; thus, shaking frequency is a critical factor in increasing oxygen circulation affecting growth and pigment production [40; 41].

$H$. werneckii AS1 had the maximum melanin synthesis of $0.420 \mathrm{~g} / \mathrm{L}$ when shaked at $180 \mathrm{rpm}$. In parallel with this findings, effect of agitation on Aspergillus oryzae growth, tyrosinase biosynthesis, and melanin pigment production has been documented with an optimum agitation rate of about $200 \mathrm{rpm}$ resulted in promoting melanin pigment biosynthesis to about $(0.258 \mathrm{mg} / \mathrm{ml})$ [42]. Moreover, Thaira et al. [41] found that the highest melanin production by Pseudomonas stutzeri strain HMGM-7 was found to be (248 mg/L) and was also positively affected by agitation speed of about 200 $\mathrm{rpm}$. They stated that higher and lower shaking frequencies (250 and $100 \mathrm{rpm}$ ) tend to reduce melanin production and biomass, respectively. Insufficient aeration during low shaking frequencies (100 rpm), may be the reason for the decrease in biomass production. On the other hand, shaking frequency as high as (250 rpm) negatively affected the growth and melanin biosynthesis because of generating excessive foam which resulted in reduced oxygen transfer rate.

Melanins are negatively charged, stable pigments with low solubility in both aqueous and most organic and inorganic solvents [43, 44]. Solubility characteristics of the extracted pigment from $\mathrm{H}$. werneckii AS1 were identical to standard melanin results, as well as, similar to properties of melanins reported previously from other microorganisms [42, 1, 45]. Similarly, extracellular melanin pigment synthesized by marine Nocardiopsis spp. were found to be insoluble in ethyl acetate and chloroform but were soluble in dimethylsulfoxide and alkaline water (pH 10) [46].

According to reports on the UV properties of melanin, the alkali solutions optimal absorption wavelength among the majority of melanin types lies in the range of 196-300 nm, depending on its origin. In addition, alkaline solutions of melanin exhibit a high UV region optical absorbance, which gradually diminish as it migrates to longer wavelengths. Previously mentioned unique melanin behavior may back to a kind of melanin's conjugated molecule's complex structure which engage and disperse UV light photons [47, 45].

The UV absorption characteristics of $H$. werneckii AS1 melanin with maximum point at $240 \mathrm{~nm}$ were consistent with the UV spectra of melanins from various fungi and bacteria. Melanin synthesized by Antarctic bacterium Lysobacter oligotrophicus strain 107-E2 ${ }^{\top}$ and $H$. werneckii EGYNDA08 exhibited characteristic peaks with strong absorbance in the UV region detected in the range of 200-300 nm [1,43]. Following the same manner, melanin pigment extracted from Cryptococcus rajasthanensis KY627764 showed significant absorbance peaks at $244 \mathrm{~nm}$ and $220 \mathrm{~nm}$, respectively in comparison with melanin standard [48].

In addition, the IR spectrum of $H$. wernekii AS1 derived pigment showed a number of significant peaks near $3438.31 \mathrm{~cm}^{-1}, 2927.31 \mathrm{~cm}^{-1}, 1637.53$ $\mathrm{cm}^{-1}$, and $1239.90 \mathrm{~cm}^{-1}$. The first peak revealed the presence of the $(-\mathrm{OH})$ group, the broadening of the band may be justified by linkage of the amino group $(-\mathrm{NH})$ with the $(-\mathrm{OH})$ group through hydrogen bonding [48]. While the second peak indicates the stretches of aliphatic (C-H groups). Moreover, the aromatic ring $(\mathrm{C}=\mathrm{C})$ stretching was linked to the third one. The last one represented the phenolic $(-\mathrm{OH})$ groups stretching vibration. These FTIR features have a close similarity to the typical structure of melanin [44]. Characteristic properties of the IR spectrum of $H$. werneckii AS1 pigment were similar to melanin pigment from various reported microorganisms as Klebsiella sp. GSK [49], Inonotus hispidus mushroom [45], and $H$. werneckii EGYNDA08 [1]. In accordance to the above-mentioned findings, Infrared (IR) spectrum of melanin from $H$. werneckii, halophilic black yeast, revealed 
characteristic peaks near $3,435 \mathrm{~cm}^{-1}, 2,931 \mathrm{~cm}^{-1}, 1,633 \mathrm{~cm}^{-1}$, and $1,267 \mathrm{~cm}^{-1}$, respectively [50]. Furthermore, melanin pigments from Cryomyces antarcticus, a black fungus, displayed two remarkable peaks around 2917 and $2843 \mathrm{~cm}^{-1}$. Also, as indicated in this work, those peaks were not detected in the conventional DOPA melanin spectra used for comparison [51]. Mbonyiryivuze et al. [52], however, ascribed those peaks to DOPA melanin.

In general, fungal DOPA-melanin are derived from the oxidation of L-dopa or L-tyrosine. They are remarked by having about 5.1-9\% nitrogen and $0-1 \%$ sulfur of their elemental composition, which means that they almost lacking sulfur in their structure [29;53]. Another main fungal melanin type is DHN-melanins characterized by the absence of nitrogen in their structure [54, 29, 45, 44]. From previously mentioned findings and due to acceptable $\mathrm{CHN}$ content (43.35\%, 5.644\%, and $5.48 \%$, respectively) and the concentration of sulfur $(0.877 \%)$ that is very low, we suspect that the examined pigment may be eumelanin. According to Chen et al. [55] the small quantity of sulfur may be retained during the purification steps or a small amount of a sulfur-containing protein attached to the melanin.

A nitrogen percentage varying from 5.1 to $6.7 \%$ with complete lacking of the sulfur element was documented for DOPA-melanin produced by Aspergillus nidulans strains [56]. In addition, DOPA-melanin from Inonotus hispidus mushroom revealed a similar nitrogen content of around 5.31\% with a higher sulfur content of $2.02 \%$ [45]. Boletus griseus, halophilic black yeast $H$. werneckii and Klebsiella sp. GSK all have similar findings regarding the elemental composition of melanin pigments $(50,57,58)$.

The shape and size of melanin granules vary depending on the source between $(30-1000 \mathrm{~nm})$ [44]. H. werneckii AS1 melanin was figured as definite crystals and/or yeast cells with sizes ranging from $(130-160 \mathrm{~nm})$. In harmony with the current investigation, Rani et al. [50] reported the melanin pigment derived from the halophilic black yeast $H$. werneckii to has a yeast resembling structure. In contrast, Hortaea werneckii R23 melanin was characterized to has a definite crystal shape with a defined structural order [59]. In addition, melanin pigment extracted from Mycosphaerella fijiensis mycelium was described as large clusters of compact spherical granules ranging in diameter between (100-300 nm) [60].

The productivity pattern of $H$. werneckii AS1 melanin showed a slow exponential phase output, which increased till obtaining the onset at the stationary phase in the 10th day with about $0.44 \mathrm{~g} / \mathrm{L}$. A similar behavior was documented in previous studies for other microorganisms as Aspergillus bridgeri, Actinoalloteichus sp, and Yarrowia lipolytica [31, 26, 34]. On the contrary, melanin production by the halophilic black yeast $H$. werneckii showed incubation periods shorter than 10 days and the maximum yield of crude melanin was $5.60 \mathrm{~g} / \mathrm{L}$ extracted on the 6 th day [50]. A decrease in melanin yield may be due to photodegradation of the pigment or by the organism itself since melanin is a photo-protective polymer [42].

Regarding the growth behavior of our isolate growth under a range of different salinities, it followed the characteristic pattern of growing without salt, as well as in a salt solution as high as (4 M) but in a slower growth rate. The findings of Saleh et al. [1] on H. werneckii EGYNDA08 are consistent with the previously mentioned results since they have documented that their isolate could survive salt concentrations up to $25 \%$, nearly saturated salt concentration, and even under the entire lack of salt. They also, observed that melanin concentration decreased by increasing salinity and they justify that with the effect of growth medium on melanization. Ultrastructural studies on $\mathrm{H}$. werneckii melanin revealed that at 0-0.85 $\mathrm{M}$ sodium chloride, a continuous thin coating of melanin granules was constructed, which can develop into a shield-like firm layer of melanin granules in the outside section of the cell wall and can also stretch into the outer layer of the cell wall at ideal salinity [25]. However, when grown under high salinities of 1.7 and 3.4 M sodium chloride, an incoherent layer of melanin granules was formed. These facts may clarify the decrease in melanin production by increasing $\mathrm{NaCl}$ concentration due to a change in its deposition structure in the cell wall.

Researches on the production of melanin from melanogenic microorganisms revealed that there is no ubiquitous media or cultivation conditions for propagating them. Moreover, the composition and ratio of each component vary regarding the isolate [61]. Hence, applying the statistical optimization designs can aid significantly in increasing the melanin yield by detecting the main factors affecting the process, besides the impact of the interaction between those valuable elements. In the present study, this technique resulted in a 2.26-fold increase in melanin yield when compared to the outcome before the whole optimization steps.

From the baseline settings, the Plackett-Burman experiment raised melanin output to $0.509 \mathrm{~g} / \mathrm{L}$ with a 1.23 -fold enhancement. In a parallel study, it was detected that after implement of Plackett-Burman design, the final melanin yield processed by Streptomyces glaucescens NEAE-H was about $19.17 \mu \mathrm{g}$ melanin/0.1 ml of medium with a 2.24 -fold increase in productivity over the basal conditions yield of $8.57 \mu \mathrm{g} / 0.1 \mathrm{ml}$ of medium. In addition, the applied Placket-Burman experiments demonstrated that the incubation duration, protease-peptone, in addition to ferric ammonium citrate were the most valuable independent factors exerting an effect on melanin synthesis [47].

After the Plackett-Burman step, Box-Behnken design was implemented to boost melanin productivity to $0.938 \mathrm{~g} / \mathrm{L}$ by improving the level and interactions between calcium chloride, trace element, and culture volume as the critical factors. In consistence with our protocol, optimization of melanin production by Aspergillus fumigatus AFGRD105 was applied through a 12-run of Plackett-Burman experiment for estimating the essential parameters, followed by Box-Behnken design optimization of relevant factors. Temperature, moisture, and sodium dihydrogen phosphate concentration have been mentioned to be the optimum variables. This optimization protocol resulted in a two-fold elevation in the melanin productivity from $3.4 \mathrm{mg} / \mathrm{L}$ to $6.6 \mathrm{mg} / \mathrm{L}$ [62].

Another study used the same approach to optimize Brevundimonas sp. SGJ productivity of melanin [63]. The best circumstances were pH 5.31, Ltyrosine $1.872 \mathrm{~g} / \mathrm{L}$, tryptone $1.440 \mathrm{~g} / \mathrm{L}$, and copper sulfate $0.0366 \mathrm{~g} / \mathrm{L}$. Melanin's outcome with these levels was $1.227 \mathrm{~g} / \mathrm{L}$ with about 3.05 -fold

Page 7/17 
increase over the melanin obtained prior to the optimization protocol.

Finally, the ability to get such a valuable pigment in a considerable amount from a non-hazardous natural source opens the door for its inclusion in a variety of essential application in diverse sectors because commercially accessible melanins are obtained either chemically or by extraction from sepia, and both ways afford hurdles in terms of yields generated that aren't suitable for large-scale applications [64]. Melanin's appealing potential to react with various metals in a process requiring numerous engaged links between metals and the pigment's carboxyl, hydroxyl, and amine functional groups facilitates its contribution in heavy metal bioremediation [65]. Regarding the field of human health, melanin can be used in multiple pharmaceutical, medical and cosmetic practices, including radioprotection, anticancer, antioxidant and antimicrobial [66].

\section{Conclusions}

Melanin pigment was synthesized and extracted from the halotolerant black yeast $H$. werneckii AS1 which was isolated from Egyptian solar saltern. $H$. werneckii AS1 can withstand salt concentration up to $4 \mathrm{M}$. Physiochemical characterization and analytical analysis of the extracted pigment using UV-Visible spectroscopy, FTIR, elemental analysis, and SEM suggested it to be a eumelanin pigment. The effect of growth conditions on melanin synthesis was evaluated by the aid of statistical methods which helped in detecting the optimum level of the most important variables. Three variables calcium chloride, trace element, and culture volume were chosen for optimization of production conditions through the Box-Behnken experiment design. The optimal combination (calcium chloride, $1.125 \mathrm{~g} / \mathrm{L}$; trace element, $0.25 \mathrm{ml} / \mathrm{L}$ and a culture volume $225 \mathrm{ml} / 500 \mathrm{ml}$ ) was obtained and the maximum melanin yield was $0.938 \mathrm{~g} / \mathrm{L}$. From the results in this study, the locally isolated $H$. werneckii AS1 can be a promising candidate for melanin production. Finally, $H$. werneckii AS1 is preserved for further studies regarding the different valuable environmental and medical applications of the produced melanin pigment.

\section{Methods}

\section{Samples collection and yeast strain isolation}

Water and sediment samples were collected from solar saltern in Egypt, exactly from Alexandria international coastal road in December 2019 was where isolation takes place. The isolation was carried out as following: one gram of sediment was suspended in $5 \mathrm{ml}$ of sterile sea water, then one milliliter of the dilution as well as from water samples, each were plated on Sabouraud dextrose agar (SDA) plates supplemented with L-tyrosine, 10\% $\mathrm{NaCl}$, and $150 \mathrm{mg} / \mathrm{l}$ chloramphenicol to avoid bacterial contamination [67, 50]. Plates were incubated at $30^{\circ} \mathrm{C}$ for 3 weeks and checked at regular intervals for detecting melanized colonies, which were purified by sub-culturing on SDA made with sea water. The pure cultures were preserved in $70 \%$ glycerol and stored at $-20^{\circ} \mathrm{C}$.

\section{Melanin Production Under Different Incubation Conditions}

Screening for melanin production in liquid medium was carried out in $500 \mathrm{ml}$ flasks holding $100 \mathrm{ml}$ of Vogel's medium [42] prepared with seawater. Afterward, for 7 days, flasks were incubated at $30^{\circ} \mathrm{C}$ in a static and shaking incubators to study and compare the impact of static and shaking modes on melanin production. For shaking condition, flasks were incubated at $180 \mathrm{rpm}$ in an orbital shaker. Prior to sterilization, the pH of the culturing medium was adjusted to 5.0-5.5 [42].

\section{Molecular Identification Of The Potent Black Yeast Strain}

The DNA was extracted from the potent black yeast strain culture at Assiut University's Molecular Biology Research Unit using a Patho-gene-spin DNA/RNA extraction kit provided by Intron Biotechnology Company, Korea. After that, the fungal DNA was transported to Daejeon, South Korea, SolGent Company for performing the polymerase chain reaction (PCR) and sequencing rRNA. ITS1 and ITS4 as forward and reverse primers for the PCR reaction were added to the reaction mixture. Primers are made up of the following sequences: ITS1 (5' - TCC GTA GGT GAA CCT GCG G - 3'), and ITS4 (5'- TCC TCC GCT TAT TGA TAT GC -3'). Through the addition of ddNTPs to the mixture of the reaction, the purified PCR product (amplicons) was sequenced using the identical primers [68]. To determine DNA similarities, the acquired sequences analysis was carried out by the aid of Basic Local Alignment Search Tool (BLAST) supported by the National Center of Biotechnology Information (NCBI) website. By the help of BioEdit sequence alignment editor (version 7.2.5), Phylogenetic study of ITS region sequences was performed using the neighbor-joining approach.

\section{Melanin extraction}

According to Gadd [69], melanin pigment was extracted and purified. After a week of incubation, the culture for approximately 10 minutes was centrifuged at 10,000 rpm, the supernatant was discarded and pellets were rinsed with distilled water then collected for the extraction step. Melanin was recovered from yeast biomass by autoclaving it with $1 \mathrm{~N} \mathrm{NaOH}$. In order to obtain the supernatant containing the desired melanin pigment, centrifugation of the treated biomass for about 10 minutes at $8000 \mathrm{rpm}$ was performed. After that, concentrated $\mathrm{HCl}$ was added to acidify the supernatant to $\mathrm{pH} 2$ followed by a centrifugation step for 10 minutes at 10,000 rpm which resulted in precipitating the melanin pigment. The extracted melanin was then dried in a dehumidified environment. 


\section{Melanin characterization}

\section{Solubility characterization}

A modified method from that described by Thomas [70] was performed to chemically analyze and define the extracted pigment. Various inorganic and organic solvents including distilled deionized water, $1 \mathrm{~N} \mathrm{HCl}, 1 \mathrm{~N} \mathrm{NaOH}$, as well as ethanol, methanol, butanol, chloroform, dimethyl sulfoxide (DMSO), hexane, and ethyl acetate, were used to test the extracted pigment solubility pattern. Using an oxidizing agent such as $\mathrm{H}_{2} \mathrm{O}_{2}$, a bleaching test was carried out. In addition, $1 \% \mathrm{FeCl}_{3}$ solution was used to test the precipitation nature of the pigment. All of these tests were done in conjunction with synthetic melanin.

\section{Spectrophotometric analysis}

spectrophotometric examination of the extracted pigment was administrated using UV-visible spectrophotometer over a wide wavelength range (200$800 \mathrm{~nm}$ ). A solution of $1 \mathrm{~N} \mathrm{NaOH}$ was used to dilute the pigment (1:10). As a control, a melanin standard (Sigma Aldrich; reference M8631) has been analyzed following the same steps [1].

\section{Fourier transform-infrared (FT-IR) spectrum analysis}

Using an IR spectrometer (PerkinElmer, USA), the extracted pigment's FTIR spectrum was detected. The spectra were recorded in the wave region of $400-4000 \mathrm{~cm}^{-1}$ by using $\mathrm{KBr}$ pellets obtained from a mixtures of spectral grade $\mathrm{KBr}$ and pigment sample uniformly pressed under vacuum. The reported result was compared against a genuine standard melanin (Sigma Aldrich, reference: M8631) [30].

\section{Elemental analysis}

An elemental analyzer (Vario MACRO cube, Elementar, Germany) was used to detect the content of carbon, nitrogen, hydrogen, and sulphur in percent for the extracted melanin pigment. The working parameters were 0.1 percent standard deviation and $950-1200{ }^{\circ} \mathrm{C}$ digesting temperatures. Final products including $\mathrm{CO}_{2}, \mathrm{H}_{2} \mathrm{O}, \mathrm{NO}$, and $\mathrm{SO}_{2}$ were formed from the oxidation of the analyzed products carbon, hydrogen, nitrogen and sulfur oxidize, respectively $(45,57)$. The elemental composition was determined by collecting these products and estimating their weights.

\section{Scanning electron microscope}

The extracted pigment was covered with a coat made of gold to examine their morphological and surface structure using JEOL (JSM-IT200) scanning electron microscope (SEM) at the required magnification and an acceleration voltage of $20 \mathrm{kV}$.

\section{Enhancement of culture conditions for optimizing melanin pigment production} Incubation period effect on melanin production

The synthesis of melanin by the chosen yeast strain was evaluated in $500 \mathrm{ml}$ flasks containing 100 ml of Vogel's medium at different incubation times ranging from 5 to 10 days [71]. For each incubation period, cultures were incubated at $30^{\circ} \mathrm{C}$ in an orbital shaker at $180 \mathrm{rpm}$, and biomass dry weight $(\mathrm{g})$ and melanin yield $(\mathrm{g} / \mathrm{l})$ were measured.

\section{Different sodium chloride concentrations effect on both growth of the isolate and melanin production}

The purpose of the salinity test was to indicate how varying sodium chloride concentrations affected the propagation and generation of melanin by the isolate under examination. Cells were cultured on Vogel's medium prepared with sea water and with the addition of different NaCl concentrations $10,20,30$, and $40 \%(w / v)$. In addition, a flask with Vogel's medium prepared with distilled water was prepared to investigate the ability of the isolate to grow and produce melanin in the absence of $\mathrm{NaCl}$. Inoculated media containing black yeast were incubated in a rotary shaker at $180 \mathrm{rpm}$ for about 10 days at $30^{\circ} \mathrm{C}$. The resulting melanin, at the end of the growth period and the manifestation of the black color, was derived and estimated [1, 22].

\section{Optimization of different medium conditions by Plackett- Burman (PB) design experiment}

Plackett-Burman experimental design was used to optimize several factors utilizing a statistical approach for maximum melanin synthesis [72]. PB design is a sort of two-level fractional factorial design that have the advantage of selecting the most important factors from a group of candidates by applying the fewest number of tests [62]. The goal of this optimization process is to figure out which medium elements have a high impact on melanin pigment formation. In this study, 12 experimental runs were used to screen 11 variables, including 7 medium component variables in addition to $\mathrm{pH}$, culture age, inoculum size and culture volume. Each variable was examined at high (+) and low (-) levels, with each trial being performed twice. The following formula was used to calculate each factor's main effect:

$\operatorname{Exi}=\left(M i_{+}-M i-\right) / N$ 
Where Exi is the main effect of the variable, and $\mathrm{Mi}$ and $\mathrm{Mi}$-are the melanin yields $(\mathrm{mg})$, where the independent variable is present in high and low concentrations respectively, and $N$ is the number of trials divided by two. To determine the variable significance, "Microsoft Excel 2019 " was used to calculate statistical $t$-values of equal unpaired samples.

\section{Optimization of growth parameters using Box Behnken (BB) design}

For gaining the optimum rank of the fundamental factors that was picked up using PB experiment, BB design was conducted using independent positive variables produced after PB design. Each single variable was investigated at different three levels of low, moderate and high $(-1,0,+1)$. A total of 15 tests were carried out with three variables in the experimental design. The calculated response was melanin productivity ( $\mathrm{g} / \mathrm{l}$ ) [62]. 3D surface plots were created to better understand the interactions between variables and to predict the optimum concentration of each component. The optimal medium composition for melanin synthesis was determined using a second-order polynomial model:

$$
Y=\beta_{0}+\Sigma \beta_{i} X_{i}+\Sigma \beta_{i i} X_{i i}+\Sigma \beta_{i j} X_{i j}
$$

where $\beta i$ donates the regression coefficients of regression for individual factor effect, $\beta$ ii represents the regression coefficients for factor square effects, and $\beta i j$ is the regression coefficients for factors interactions. based on the analysis result(s), validation test for BB experiment were established [1]. Also, all statistical analyses and graphics were generated using STATISTICA 14.0 software and Microsoft Excel 2019.

\section{Nucleotides accession numbers}

The consensus sequences were generated through BioEdit sequence alignment editor (version 7.2.5), and then examined by adopting the BLAST tool (National Center for Biotechnology Information (NCBI) https://www.ncbi.nlm.nih.gov/) [73]. The acquired 18s rRNA sequence was deposited in the GenBank with the number of accession MW187022. A web link for the dataset and accession number is mentioned at "Availability of data and materials" section.

\section{Declarations}

\section{Ethics approval and consent to participate}

Not applicable.

\section{Consent for publication}

Not applicable.

Availability of data and materials

All data generated or analysed during this study are included in this published article [and its supplementary information files].

Regarding the nucleotides accession number " The datasets generated and analysed during the current study are available in the [National Center for Biotechnology Information (NCBI) https://www.ncbi.nlm.nih.gov/] repository, and [The acquired 18s rRNA sequence was deposited in the GenBank with the number of accession MW187022 (https://www.ncbi.nlm.nih.gov/nuccore/MW187022)].

\section{Competing interests}

The authors declare that they have no competing interests.

\section{Funding}

No funding was received.

\section{Authors' Contribution}

$\mathrm{AE}, \mathrm{HK}, \mathrm{SH}, \mathrm{KG}$ conceived and designed research. $\mathrm{AE}$ conducted experiments. $\mathrm{AE}, \mathrm{SH}$, and HK contributed for analyzing data. $\mathrm{AE}$ wrote the manuscript. All authors revised the manuscript. All authors finalized and agreed to the final version of the manuscript.

\section{Acknowledgements}

Not applicable.

\section{References}

1. Saleh H, Abdelrazak A, Elsayed A, El-Shishtawy H, Osman Y. Optimizing production of a biopesticide protectant by black yeast. Egypt J Biol Pest Co. 2018;28:72. 
2. Martínez LM, Martinez A, Gosset G. Production of melanins with recombinant microorganisms, Front Bioeng Biotechnol. 2019;7:1-14.

3. Kutty S, Lawman D, Singh I, Philip R. Black yeasts from the slope sediments of Bay of Bengal: phylogenetic and functional characterization. Mycosphere. 2013;4:346-361.

4. Sepcic K, Zalar P, Gunde-Cimerman N. Low water activity induces the production of bioactive metabolites in halophilic and halotolerant fungi. Mar Drugs. 2010;9:43-58.

5. Kejzar A, Gobec S, Plemenitas A, Lenassi M. Melanin is crucial for growth of the black yeast Hortaea werneckii in its natural hypersaline environment. Fungal Biol. 2013;117:368-379.

6. Sajid S, Akbar N. Applications of fungal pigments in biotechnology. Pure Appl Biol. 2018;7:922-930.

7. de Hoog GS. Ecology and evolution of black yeasts and their relatives. Stud Mycol. 1999;43:3-4.

8. Gunde-Cimerman N, Zalar P. Extremely halotolerant and halophilic fungi inhabit brine in solar salterns around the globe. Food Technol Biotechnol. 2014;52:70-179.

9. Chen X, Xing XK, Zhang LC, Xing YM, Guo SX. Identification of Hortaea werneckii isolated from mangrove plant Aegiceras comiculatum based on morphology and rDNA sequences. Mycopathologia. 2012;174:457-466.

10. Brenner M, Hearing VJ. The protective role of melanin against UV damage in human skin. Photochem Photobiol. 2008;84:539-549.

11. Ahmad S, Lee SY, Kong HG, Jo EJ, Choi HK, Khan R, Lee SW. Genetic determinants for pyomelanin production and its protective effect against oxidative stress in Ralstonia solanacearum. PLOS One. 2016;11:e0160845.

12. Zalar P, Novak M, De Hoog G, Gunde-Cimerman GN. Dishwashers a man-made ecological niche accommodating human opportunistic fungal pathogens. Fungal Biol. 2011;115:997-1007.

13. Eisenman HC, Casadevall A. Synthesis and assembly of fungal melanin. Appl Microbiol Biotechnol. 2012;93:931-940.

14. Gessler NN, Egorova AS, Belozerskaya TA. Melanin pigments of fungi under extreme environmental conditions (Review). Appl Biochem Microbiol. 2014;50:105-113.

15. Nazareth SW. The world of halophilic fungi. Mycol Soc India (Kavaka). 2014;42:131-144.

16. Musa H, Kasim FH, Nagoor Gunny AA, Gopinath SCB. Salt-adapted moulds and yeasts: potentials in industrial and environmental biotechnology. Process Biochem. 2018;69:33-44.

17. Chung D, Kim H, Choi HS. Fungi in salterns. J Microbiol. 2019;57:717-724.

18. Gunde-Cimerman N, Zalarb P, De Hoog S, Plemenitasd A. Hypersaline waters in salterns-natural ecological niches for halophilic black yeasts. FEMS Microbiol Ecol. 2000;32(3):235-240.

19. Gunde-Cimerman N, Ramos J, Plemenitasd A. Halotolerant and halophilic fungi. Mycological Res. 2009;113:1231-1241.

20. Hodhod M, Gaafar A, Al-Shameri A, Qahtan A, Noor A, Abdel-Wahab M. Molecular characterization and bioactive potential of newly identified strains of the extremophilic black yeast Hortaea werneckii isolated from Red Sea mangrove. Biotechnol Biotechnol Equip. 2020;34:1288-1298.

21. Brauers G, Ebel R, Edrada R, Wray V, Berg A, Grafe U, et al. Hortein, a new natural product from the fungus Hortaea werneckii associated with the sponge Aplysina aerophoba. J Nat Prod. 2001;64:651-652.

22. De Leo F, Lo Giudice A, Alaimo A, De Carlo G, Rappazzo AC, Graziano M, et al. Occurrence of the black yeast Hortaea werneckii in the Mediterranean Sea. Extremophiles. 2019;23:9-17.

23. Gunde-Cimerman N, Plemenitas A. Ecology and molecular adaptations of the halophilic black yeast Hortea werneckii. Rev Environ Sci Biotechnol. 2006;5:323-331.

24. Jacobson ES, Ikeda R. Effect of melanization upon porosity of the cryptococcal cell wall. Med Mycol. 2005;43:327-333.

25. Kogej T, Stein M, Volkmann M, Gorbushina AA, Galinski EA, Gunde-Cimerman N. Osmotic adaptation of the halophilic fungus Hortea werneckii: role of osmolytes and melanization. Microbiology. 2007;153:4261-4273.

26. Manivasagan P, Venkatesan J, Senthilkumar K, Sivakumar K, Kim SK. Isolation and characterization of biologically active melanin from Actinoalloteichus sp. MA-32. Int J Biol Macromol. 2013;58:263-274.

27. ElObeid AS, Kamal-Eldin A, Abdelhalim MAK, Haseeb AM. Pharmacological properties of melanin and its function in health. Basic Clin Phamacol Toxicol. 2017;120:515-522.

28. Kurian NK, Nair HP, Bhat SG. Evaluation of anti-inflammatory property of melanin from marine Bacillus sp. BTCZ31. Asian J Pharm Clin Res. 2015;8:251-255.

29. Huang L, Liu M, Huang H, Wen Y, Zhang X, Wei Y. Recent advances and progress on melanin-like materials and their biomedical applications. Biomacromolecules. 2018;19:1858-1868.

30. Kumar CG, Mongolla P, Pombala S, Kamle A, Joseph J. Physicochemical characterization and antioxidant activity of melanin from a novel strain of Aspergillus bridgeri ICTF-201. Lett Appl Microbiol. 2011;53:350-358.

31. Kumar CG, Sahu N, Reddy GN, Prasad RBN, Nagesh N, Kamal A. Production of melanin pigment from Pseudomonas stutzeri isolated from red seaweed Hypnea musciformis. Lett Appl Microbiol. 2013;57:295-302. 
32. d'Ischia M, Wakamatsu K, Cicoira F, Di Mauro E, Garcia-Borron J, Commo S, et al. Melanin and melanogenesis: From pigment cells to human health and technological applications. Pigment Cell Melanoma Res. 2015;28:520-544.

33. Mahmoud YAG. Uptake of radionuclides by some fungi. Mycobiology. 2004;32:110-114.

34. Ben Tahar I, Kus-Liśkiewicz M, Lara Y, Javaux E, Fickers P. Characterization of a non-toxic pyomelanin pigment produced by the yeast Yarrowia lipolytica. Biotechnol Prog. 2020;36(2):e2912.

35. Pombeiro-Sponchiado SR, Sousa GS, Andrade JCR, Lisboa HF, Gonçalves CR. Production of melanin pigment by fungi and its biotechnological applications. In Melanin; InTech, London, UK, (2017).

36. Cochran WG, Snedecor GW. Statistical Methods, lowa State University Press. Ames, lowa, 50014, 466; 1989.

37. Gunde-Cimerman N, Plemenitaš A, Oren A. Strategies of adaptation of microorganisms of the three domains of life to high salt concentrations. FEMS Microbiol Rev. 2018;42:353-375.

38. Zalar P, Zupančič J, Gostinčar C, Zajc CJ, de Hoog GS, De Leo F, et al. The extremely halotolerant black yeast Hortaea werneckii - a model for intraspecific hybridization in clonal fungi. IMA Fungus. 2019;10:10.

39. Elsayed A, Mowafy AM, Soliman HM, Gebreil A, Magdy NI. Characterization of new strains of Hortaea werneckii isolated from salt marshes of Egypt. Egypt J Basic Appl Sci. 2016;3:350-356.

40. Hermann R, Walther N, Maier U, Büchs J. Optical method for the determination of the oxygen-transfer capacity of small bioreactors based on sulfite oxidation. Biotechnol Bioeng. 2001;74 (5):355-363.

41. Thaira H, Raval K, Manirethan V, Balakrishnan RM. Melanin nano-pigments for heavy metal remediation from water. Sep Sci Technol. 2018; 54:265-274.

42. El-Batal Al, Al Tamie MSS. Optimization of melanin production by Aspergillus oryzae and incorporation into silver nanoparticles. Der Pharm Lett. 2016;8:315-333.

43. Kimura T, Fukuda W, Sanada T, Imanaka T. Characterization of water-soluble dark- brown pigment from Antarctic bacterium, Lysobacter oligotrophicus. J Biosci Bioeng. 2015;120(1):58-61.

44. Pralea IE, Moldovan RC, Petrache AM, Ilieș M, Hegheș SC, lelciu I, et al. From extraction to advanced analytical methods: the challenges of melanin analysis. Int J Mol Sci. 2019;20(16):3943.

45. Hou R, Liu X, Xiang K, Chen L, Wu X, Lin W, et al. Characterization of the physicochemical properties and extraction optimization of natural melanin from Inonotus hispidus mushroom, Food Chem. 2019;277:533-542.

46. Kamarudheen N, Naushad T, Rao BKV. Biosynthesis, characterization and antagonistic applications of extracellular melanin pigment from marine Nocardiopsis Sps. Indian J Pharm Educ Res. 2019;53(2):112-120.

47. El-Naggar NEA, El-Ewasy SM. Bioproduction, characterization, anticancer and antioxidant activities of extracellular melanin pigment produced by newly isolated microbial cell factories Streptomyces glaucescens NEAE-H. Sci Rep. 2017;7:42129.

48. Barretto DA, Kumar S. Biological activities of melanin pigment extracted from Bombyx mori gut-associated yeast Cryptococcus rajasthanensis KY627764. World J Microbiol Biotechnol. 2020;36:1-17.

49. Shrishailnath S, Kulkarni G, Yaligara V, Kyoung L, Karegoudar T. Purification and physiochemical characterization of melanin pigment from Klebsiella sp. GSK. J Microbiol Biotechnol. 2010;20:1513-1520.

50. Rani MHS, Ramesh T, Subramanian J, Kalaiselvam M. Production and characterization of melanin pigment from halophilic black yeast Hortaea werneckii. Int J Pharma Res Rev. 2013;2:9-17.

51. Pacelli C, Cassaro A, Maturilli A, Timperio AM, Gevi F, Cavalazzi B, et al. Multidisciplinary characterization of melanin pigments from the black fungus Cryomyces antarcticus. Appl Microbiol Biotechnol. 2020;104:6385-6395.

52. Mbonyiryivuze A, Mwakikunga B, Dhlamini SM, Maaza M. Fourier transform infrared spectroscopy for sepia melanin. Phys Mat Chem. 2015;3(2): 25-29.

53. Suwannarach N, Kumla J, Watanabe B, Matsui K, Lumyoung S. Characterization of melanin and optimal conditions for pigment production by an endophytic fungus, Spissiomyces endophytica SDBR-CMU319. PLoS ONE. 2019;14(9):e0222187.

54. Kutty SN. Marine yeasts from the slope sediments of Arabian Sea and Bay of Bengal, Ph.D. Thesis, Cochin University of Science and Technology, Cochin, India; 2009.

55. Chen SR, Jiang B, Zheng JX, Xu GY, Li JY, Ning Y. Isolation and characterization of natural melanin derived from silky fowl (Gallus gallus domesticus Brisson). Food Chem. 2008;111(3):745-749.

56. Gonçalves, RCR, Lisboa HCF, Pomberio-Spochiado SR.Characterization of melanin pigment produced by Aspergillus nidulans. World J Microbiol Biotechnol. 2012;28(4):1467-1474.

57. Sajjan SS, Anjaneya O, Kulkarni GB, Anand SN, Suresh BM, Karegoudar TB. Properties and functions of melanin pigment from Klebsiella sp. GSK, Korean J Microbiol Biotechnol. 2013;41:60-69.

58. Liu Q, Xiao J, Liu B, Zhuang Y, Sun L. Study on the Preparation and Chemical Structure Characterization of Melanin from Boletus griseus. Int J Mol Sci. 2018;19(12):3736. 
59. Wilson W. Bioactive glucan and melanin from marine yeasts: characterization and evaluation. Ph.D. Thesis, Cochin University of Science and Technology, Cochin, India; 2016.

60. Beltran-Garcia MJ, Prado FM, Oliveira MS, Ortiz-Mendoza D, Scalfo AC, Pessoa A Jr, et al. Singlet molecular oxygen generation by light-activated DHN-melanin of the fungal pathogen Mycosphaerella fijiensis in black sigatoka disease of bananas. PLoS ONE. 2014;9(3):e91616.

61. Tran-Ly AN, Reyes C, Schwarze FWMR, Ribera J. Microbial production of melanin and its various applications. World J Microbiol Biotechnol. 2020;36:170.

62. Raman NM, Shah PH, Mohan M, Ramasamy S. Improved production of melanin from Aspergillus fumigatus AFGRD105 by optimization of media factors. AMB Express. 2015;5:72.

63. Surwase SN, Jadhav SB, Phugare SS, Jadhav JP. Optimization of melanin production by Brevundimonas sp. SGJ using response surface methodology. 3 Biotech 2013;3(3):187-194.

64. Wang Z. Melanin produced by the fast-growing marine bacterium Vibrio natriegens through heterologous biosynthesis: characterization and application. Appl Environ Microbiol. 2020;86:e02749-19.

65. Cordero R, Vij R, Casadevall A. Microbial melanins for radioprotection and bioremediation. Microb Biotechnol. 2017;10(5):1186-1190.

66. Mattoon ER, Cordero R, Casadevall, A. (2021). Fungal Melanins and Applications in Healthcare, Bioremediation and Industry. J Fungi. 2021;7(6):488.

67. Evans S, Hansen RW, Schneegurt M. Isolation and characterization of halotolerant soil fungi from the great salt plains of Oklahoma, Cryptogam. Mycol. 2013;34:329-341.

68. White TJ, Bruns T, Lee S, Taylor J. Amplification and direct sequencing of fungal ribosomal RNA genes for phylogenetics. In: Innis, MA, Gelfand DH, Sninsky JJ, White TJ, editors. PCR protocols: A guide to methods and applications, Academic Press, San Diego, U.S.A; 1990. p. $315-322$.

69. Gadd G. Effects of media composition and light on colony differentiation and melanin synthesis in Microdochium bolleyi. Trans Br Mycol Soc. 1982;78:115-122.

70. Thomas M. Modern methods of plant analysis. In: Paech K, Tracey MV, editors. Melanin, Springer-Verlag, Berlin; (1955). Vol. 4. p. $661-675$.

71. El-Gamal MS, el-Bialy HA, elsayed MA, Khalifa MA. Isolation and characterization of melanized yeast form of Aureobasidium pullulans and physiological studies on the melanization process. J Nucl Tech Appl Sci. 2017;5:57-72.

72. Plackett RL, Burman JP. The design of optimum multifactorial experiments. Biometrika. 1946;33:305-325.

73. Altschul SF, Gish W, Miller W, Myers EW, Lipman DJ. Basic local alignment search tool. J Mol Biol. 1990;215(3):403-410.

\section{Figures}




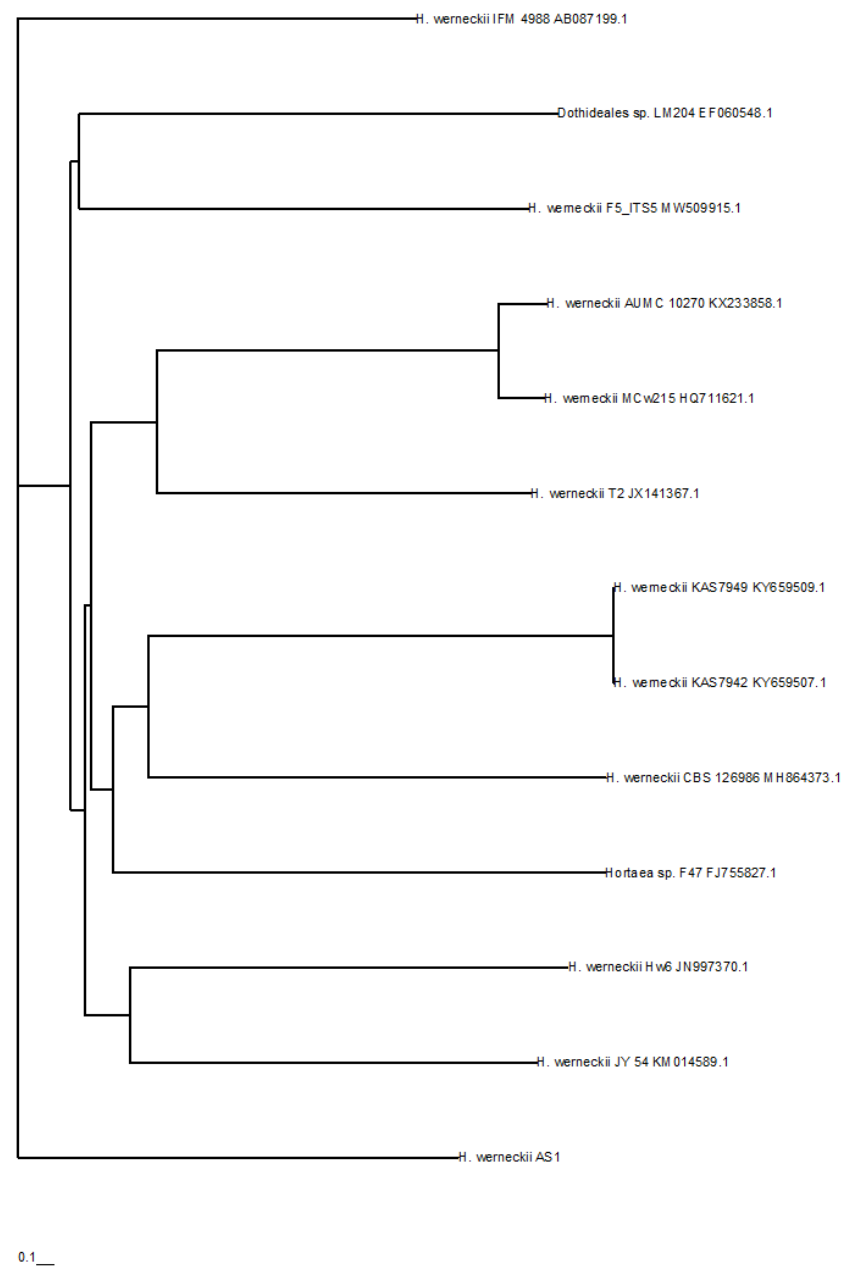

Figure 1

Phylogenetic tree based on ITS sequences showing the position of strain for Hortaea werneckii AS1. These phylogenetic relationships were identified by BioEdit sequence alignment editor (version 7.2.5).

\section{Figure 2}

UV-visible spectral properties of (a) Hortaea werneckii AS1 pigment and (b) standard melanin. 

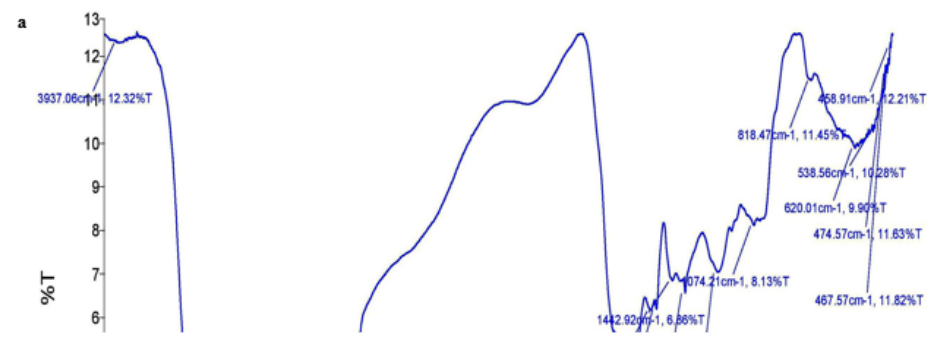

Figure 3

FTIR spectrum of (a) Hortaea werneckii AS1 pigment and (b) standard melanin showing number of the pigment characteristic peaks. 


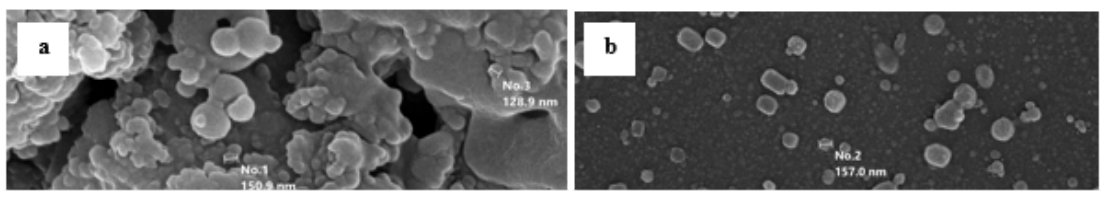

\section{Figure 4}

SEM analysis of melanin (a) overall view of Hortaea werneckii AS1 pigment, (b) focused view showing size of Hortaea werneckii AS1 melanin crystals (c) overall view of synthetic melanin and (d) size of synthetic melanin crystals. 
(a)

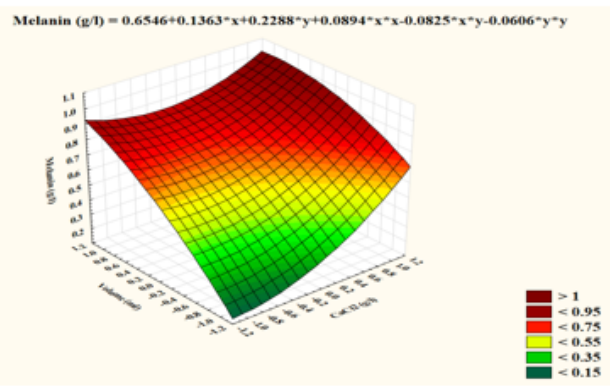

(b)

Melanin $(g / f)=0.6038+0.1363^{-} x+0.015^{*} y+0.0958^{*} x^{*} x-0.045^{*} x^{*} y+0.0283^{-} y^{*} y$

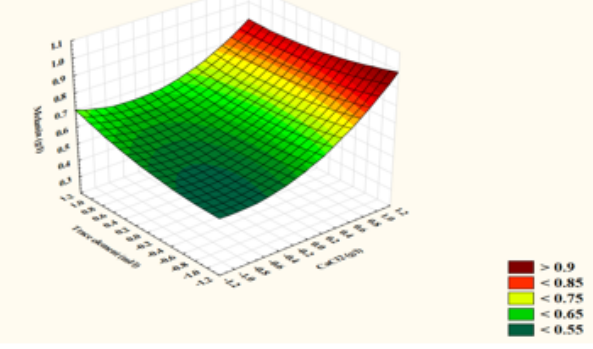

(c)

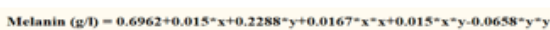

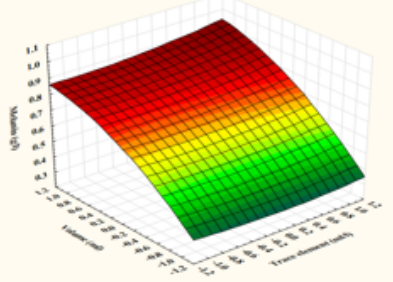

\section{Figure 5}

Three-dimensional surface plots showing the relationships between the tested significant variables and pigment formation by Hortaea werneckii AS1 and the optimal levels of the three factors as obtained from the maximum of the polynomial model. The three figures indicate (a) the interaction between $\mathrm{CaCl}_{2}$ and culture volume, (b) the interaction between $\mathrm{CaCl}_{2}$ and trace element and (c) the interaction between trace element and culture volume.

\section{Supplementary Files}

This is a list of supplementary files associated with this preprint. Click to download.

- Supplementarymaterial.pdf 